\title{
Application of Schema Theory in College English Listening Teaching
}

\author{
Jie Du* \\ School of foreign languages \\ Jingdezhen Ceramic Institute \\ Jingdezhen, China \\ sallydj@126.com
}

\begin{abstract}
This paper aims to analyze the efficiency that can be brought about in college English teaching through the application of Schema Theory. It has developed by firstly focusing on the three classifications of Schema Theory, linguistic schema, content schema, and formal schema and two major models of information processing, bottom-up and top-down. The major effort is on the investigation of integrating the theoretical framework of the Schema Theory in English listening teaching typically featured with three stages: pre-listening, while-listening and post-listening. It has been found that in theoretically oriented listening, students, who have become active participators instead of passive listener, get fully prepared by investing themselves with his prior knowledge from the perspectives of form, content, and style of the oncoming materials. Educated predictions are made based on the schemata associated with the material and students are enabled to make judgments and adjustments in the listening process to meet the demands of the task and achieve a final evaluation with the help from the teacher. Meanwhile, students tend to update his previous schema and complete an improved and more systematic schema thus efficiently advance their listening proficiency.
\end{abstract}

Keywords-Schema Theory; College English Teaching; Application; Three-staged features

\section{INTRODUCTION}

Among the four linguistic skills, namely listening, speaking, reading and writing, listening is a part failed to be attached great importance to for a long time. Because of that, listening has been the weak link for college students. However, the traditional ways of listening teaching, which viewed students as passive recipients of information, has made little progress in improving students' listening ability because they were unable to activate students to take the initiative to actively participate. Schema Theory, which has been proved to be very effective in reading comprehension, was applied in English listening teaching and the result turned out to be quite profitable.

\section{SCHEMA THEORY}

\section{A. Definition of Schema Theory}

A schema is a knowledge stored in memory that functions in the interpreting process of new information.

Frederick Bartlett, British Psychologist, first used schema as "an active organization of past reactions or of past experiences which must always be supposed to be operating in well-adapted organic response" and schemata as "structures of information stored previously in our memories” in his book Remembering.(1932: 20) It primarily communicates the concept that new information is comprehended and analyzed by a comparison with a series of associated or similar information that stored previously in mind. The new information is thus perceived in terms of its derivation from the stereotypical version.

Rumelhart, an American human intelligence expert, claimed that a schema is the data structure for representing the generic concepts stored in memory. He held that all knowledge is stored and categorized into units which are called schemata. The knowledge about how information is used is embedded in these units (1980)

\section{B. Classification of Schema}

Schema has been classified into different types in accordance with different roles. The most preferred and widely accepted one is from an American psychologist William James (1892). He categorized schema into three types, namely linguistic schemata, content schemata, and formal schemata.

\section{1) Linguistic schema}

Linguistic schema refers to the previous knowledge of a language acquired by the learner. It can be very basic linguistic units like phonemes to syllables, words, phrases, and sentences to higher-level elements like paragraphs, passages, or discourse. It can either be the tone, grammar, or cohesive devices. Linguistic schema plays a primary role in listening comprehension. Without a solid foundation of the above linguistic basics, it is almost impossible to get the thorough meaning of the target language. For example, a short dialog from $21^{\text {st }}$ Century College English, ( $2^{\text {nd }}$ Ed.)

M: Do you have notes from Professor Smith's economic class Friday? I missed class that day.

W: Guess we are in the same boat!

$Q$ : What is the woman implying?

a. He should take better notes during Professor Smith's class.

b. They both missed class because they were sailing.

c. She is not interested in economics. 
d. She missed Friday's class too. (Xiangjun zhai, pp. 195)

In the above short conversation, "in the same boats" may become the point that blocks the understanding. If the listener does not know it means "having similar experience or situations", he is likely to hold or guess it's sailing related because of the word boat. In this sense, the linguistic ability is playing a critical role in listening comprehension and teachers should repeatedly inspire and urge students to put enough energy and spirit on language learning.

\section{2) Content Schema}

Content schema, also known as topic schema, refers to the general or specific knowledge of a given topic. It provides people with a foundation for comprehension. The content schema contains previous experience with a field, topic familiarity, and social or cultural knowledge. Content schema enables listeners to make assumptions or interference, and remove ambiguities. It is proved that the more the listener is familiar with the related topic, the more likely he achieves a better comprehension of the material. Though linguistic skills are fundamentals, language, as the carrier of meanings and culture, will never be better understood without content interpreting of the genuine meaning. In addition, provision with related knowledge can help to make predictions and evaluate useful information.

For example, if a listening material is about sports, say baseball, a listener who is familiar with the baseball game would definitely do better than the one who is not interested in sports and thus knows little about baseball(two listeners linguistic skills are almost at the same level)

\section{3) Formal Schema}

Formal schema, which is also called textual schema, refers to the "background knowledge about differences among rhetorical structures, such as differences in genre, differences in the structures of fables, simple stories, scientific texts, newspaper articles, poetry, and so forth." For instance, the style of an academic paper differs greatly from a news report. Likewise, a scientific essay is nothing like a fable. With the formal schema, listeners are to be reminded to give heed to the genre of the material before listening.

To take news report as an instance, usually, the first sentence is the topic sentence that generalizes the whole story and tends to answer $5 \mathrm{~W}+\mathrm{H}$ (When, What, Where, Who, and How) questions. Therefore, the listener should be guided intentionally to pay special attention to the first sentence.

\section{THEORETICAL FRAMEWORK OF LISTENING COMPREHENSION}

According to Vandergrift(1999), listening is a complex active process in which the listener must discriminate between sounds, understand vocabulary and grammatical structures, interpret stress and intonation, retain what is gathered in the above, and interpret within the immediate and larger social-cultural context of the utterance.
Obviously, listening comprehension is not a simple passive process of receiving the sounds; it involves assigning meanings to the sounds with the related background knowledge of the language, topic and form of the text. Thus it is an interrelated process of effective interpretation of the input sounds.

\section{A. Bottom-up processing}

The bottom-up processing model, also data-driven processing model, arose in the 1940s, and developed in the 1950s, involves knowledge of the language system that allows the learner to separate and make recognition on the acoustic signal as sounds forming words, which would form phrases or clauses by a unified intonation contour, and phrases or clauses that would form cohesive and coherent texts lead to all levels of language analysis come into play (Celce-Murcia, 1995). In this model, listeners tend to use fundamental linguistic units from the lowest level to a higher level in order to achieve the comprehension of the texts. If the whole listening process is viewed as decoding of the input language, then the decoding system starts with the elements like phonemes, syllables, words, phrases and ends with the understanding of the sentences to the discourse. It is as a result from bottom to up or from micro to macro process.

\section{B. Top-down processing}

Top-down processing model, also known as conceptdriven or knowledge-driven processing, "is sometimes regarded as macro-processing, and involves the stimulation of schematic knowledge and context knowledge” according to Celce-Murcia (1995), It refers to meaning from "contentual clues" and from making blinks between the spoken message and various types of the "prior knowledge" listeners hold in their heads.

Unlike bottom-up processing, in the top-down process model, listeners resort to prior knowledge of schema rather than independent acoustic units to interpret the input text. It stresses the use of real-world knowledge previously acquired and stored in memory and cognitive ability. The prior knowledge can be background information about the topic and physical context of the utterance. It occurs when the listeners make general predictions and search the key information in the incoming input to fit or prove the predictions. Because listeners are active searchers of meanings in the listening process, they make predictions and educated guesses depending on their content and formal schema.

To some degree, top-down process model seems scientific, however, it overemphasizes the functions of schema and contextual knowledge while ignores the roles of linguistic competence, which makes this model unsatisfactory. 


\section{THE APPLICATION OF SCHEMA THEORY TO THREE- STAGE FEATURED LISTENING}

Modern language teaching, unlike conventional methods which emphasizes product, put much stress on the process which can offer a holistic view of how the information is processed. Listening process can be further divided into three stages, namely pre-listening, while-listening, and postlistening. The application of Schema Theory to those stages has been proved to be useful in promoting students' listening skills.

\section{A. Pre-listening process}

Pre-listening process, as a lead-in, is a major part in which schema is to be activated and get ready for the actual listening. Vandergrift (1999) holds that "pre-listening activities are crucial to good second language pedagogy. During this critical phase of the listening process, teachers should prepare students what they will hear and what they are expected to do.”

According to the Schema Theory, the process of the interpretation should obey certain principles that every input is mapped against some existing background knowledge and that all aspects of that schema must be compatible with the input information. Schema is a cognitive framework where information is stored in a systematic manner. Every person establishes his own particular styles of long-time memory schema based on his unique life experience and educational background. Carrel (1983) claims that the pre-listening activities should compose of both new background knowledge building and existing background knowledge activating.

Before listening, the teacher should familiarize students with corresponding background information related to the oncoming materials; this effort is to function as an activator to light students' content schema and in turn to help them make predictions about the possible content. Teachers can also assign students into groups to discuss the possible meanings and make predictions together. For example, when the teacher informs students that the material is about a sport event, the Olympic Games, students should voluntarily search what they know about it. The origin of the game, the Olympic spirit, what events are included, some anecdotes or interesting stories from this big game, and the cities that held the game so long and so forth should be dug out from memory. Meanwhile, teachers can add more to the list if they find what students obtained is not enough to handle the material.

For instance, if the material is about the body language, the teacher should arrange a little discussion and invite students to talk about the meanings of the widely used body languages in the culture they know well. After that, the teacher can demonstrate a particular body position, say, folding his arms in front of his chest, and encourage students to conjecture the possible meanings it may convey. Students may venture words like aggressive, unfriendly, cold, distant etc. Students can be also reminded to take notes for usually one specific body position or gesture can convey more the one meaning or different meanings in a different culture. During discussion and interaction like this, students' knowledge of body language and their implications can be reviewed and activated effectively and their content schema is thus in mission and gets ready for the actual listening part.

Teachers can also analyze the key words, expressions and language points which may carry important meanings in comprehending the materials. In terms of language, the fundamental schema is a semantic scheme or linguistic schema. With proficient linguistic competence, listeners' other relevant schema can be activated in the listening process. Thus, via putting emphasis on the above linguistic units, listeners schema of language can be enlightened.

For example, if teachers tell students in advance that the oncoming material is about asking for the directions, students would initiate related dialogue schema with the words like directions, names of places being given priority. In fact, by doing so, students set up a pretty clear projected schema to get ready for the actual listening.

On top of the above two, students are to be acquainted with the style, namely, formal content through which to predict the features and structure of the material. Considering the different proficiency levels students may possess, teachers again should inform students of this. For instance, if students are to hear a news item, they are expected to activate the schema and learn that three parts heading, lead and body constitute an item of news. Moreover, news item takes two fundamental structures, namely, the inverted pyramid form and the chronological style and students need to answer W.H. questions mentioned in the previous paragraph. Take the following news item as an example:

On an island near Spain, there's a unique language used by some of the people living there. They do not use words to communicate like in most languages. They whistle...(body) Today, however, it's a dying language because now many people use modern ways of communication much faster, and many people from the island are moving to the mainland of Spain where whistling can't be used for communication. The people on the island want to preserve this special language, so they began teaching it in schools eight years ago.

If the teacher tells students in advance the heading of the news, whistling language, because which is not included in the text, students naturally would work on the following questions:

a. Who is using this special language?

b. How do they use this whistling language to communicate?

c. What is the present situation of this language?

d. Why?

e. What is the future of the language? 
Once the students are activated of their formal style, together with the other two, they unquestionably list the above questions and would search the answers in the oncoming while-listening process and this purpose-driven mode, in turn, stimulates the actual listening.

\section{B. While-listening process}

Since much work is done for the first stage, in the second while-listening process, which is also a stage hard to be controlled by the teachers, students are expected to have a general understanding of the material with limited heed paying to the key details. This stage refers to students' independent exploration and stimulating existing schema. Teachers need to give full play to the initiative and creativity and make sure they remain alert and active in thinking and analyzing. Only in this way, can students get actively involved in recognizing, decoding and screening information as required.

The listening strategy training and information processing are to be centered on the following two steps. The first step, extensive listening. Teachers remind students of resorting to "top-down" model to enable them to interpret the general idea of the text, to be aware of the tone and the structure of the material. Above all, students are required to comprehend the meaning of the text from a global view instead of clinging on to the individual linguistic segments. In addition, together with the new knowledge acquired from the material, students are to decoding linguistic obstacles such as new words and complex sentences.

The second step, intensive listening. Since well-trained listeners in the first stage get a general picture and overall prediction of the oncoming material, they need to catch specific linguistic units to prove their original generalization. Carrel holds that "Schemata are hierarchically organized, from most general at the top to most specific at the bottom. Bottom-up processing is evoked by the incoming data" students in this process are to listen to the material intensively and acquire information by decoding words using their linguistic knowledge so as to figure out the meaning of the text. In this step, students rely on the details and specific information to get the big picture.

Actually, extensive listening and intensive listening or top-down and bottom-up process can never be isolated or excluded from one another. In other words, it seldom occurred that one listener merely relies on one and neglect totally another in understanding material. So the common practice is using them both in an interactive or alternative manner. Thus, teachers play a significant role in guiding students to combine them as well. In daily lecture time training, the usual practice is one material may be played several times until student comprehends the meaning well. For example, after the first listening, students should be encouraged to make an assessment of their listening and adjust the accuracy of their original predictions, to remove some ambiguities. During the listening process, the scale to which the listeners use one processing model or the other depends much on his familiarity with the topic, his competence of the target language, and the intention of listening.

\section{Post-listening process}

In post-listening process, well-designed activities carry the same significance as those of previous stages. In this stage, students are guided by their teachers to stretch their thinking when reacting to what is absorbing and then are encouraged to work out the explicit meaning of the speech.

Listening process can either be linear or circular, it means the listeners can repeat and turn back to the original material as long as they prefer. Post-listening process is the stage in which students' new and updated schema is to be reconstructed. Teachers as judges can evaluate students' level of comprehending the material and help students to complete an improved version of the schema. This can be realized by raising questions, arranging group discussions, or retelling the stories and so on.

Vandergrift (1999) claims that the teacher can encourage self-evaluation and reflection by asking students to assess the effectiveness of strategies used. Group or class discussions on the approach taken by different students can also stimulate reflection and worthwhile evaluation.

For example, students are assigned to listen to a passage about a Western Festival Christmas. After students finish all the exercise required, they can be encouraged to report in public about the origin of the festival and how people celebrate it. Teachers can add some details to the list to help fulfill the task. By after-listening discussion, students' knowledge of Christmas can be completed and perfected.

In short, teachers in this process help students to consolidate their prior knowledge that has been activated, and mentor them to review new information and thus constructed a promoted version of the schema.

\section{CONCLUSION}

English listening teaching under the guidance of the Schema Theory is more efficient than the traditional ways because teachers are not only emphasizing on the language itself, they attach same importance to the learning of the culture and the application of scientific theory based on the various characteristics of the material which in turn lift students onto a platform on which they are guided and assisted in a systematic manner. Students taught this way to activate all the prior related schemata and they can voluntarily improve and reconstructed their schemata and resort to bottom-up and top-down process freely and interactively as needed for they consciously referring to form, content, and linguistic schema and combine them all together to achieve a better comprehension of the material. Students trained this way are capable of constructing more sophisticated schemata and in turn, it helps prove that college English listening teaching under the guidance of Schema Theory is bound to improve students' listening 
comprehension and as a result promote the efficiency of listening teaching.

\section{REFERENCES}

[1] Bartlett, F. C. Remembering: A Study in Experimental and Social Psychology. Cambridge University Press, 1932.

[2] Rumelhart, D. E. Schemata: The Building Blocks of Cognition [A]. In R J. Spiro et al.(eds.).Theoretical Issues in Reading Comprehension [C]. Hillsdale, NJ: Eelbaum. 1980

[3] James, W. Textbook of Psychology[J]. Vol. New York: Holt. 1892.
[4] Xiangjun Zhai, 21st Century College English, viewing, listening and Speaking. 2nd Ed. Shanghai: Fudan University Press. 2017, pp195.

[5] Vandergrift, Larry. 'Facilitating Second language Listening Comprehension: Acquiring Successful Strategies’ [J]. ELT Journal. 1999. 53:3.

[6] Celce-Murcia, M. "Discourse Analysis and the Teaching of Listening". In Cook, R.et al. (eds.), Principles and Practice in Applied Linguistics. Shanghai: Shanghai Foreign Language Education Press, 1995,

[7] Carrell, P. L. \& J. C. Eisterhold. "Schema Theory and ESL Reading Pedagogy”[J].TESOL Quarterly, 1983,17(4): 553-573.

[8] Shutang Zheng. New Horizon College English: Listening and Speaking. Beijing, Foreign Language Teaching and Research Press. 2017, pp.83. 